\title{
An Ecological Study of Community-Level Correlates of Suicide Mortality Rates in the Flemish Region of Belgium, 1996-2005
}

\author{
Marc Hooghe, PhD, and Bram Vanhoutte, MA
}

\begin{abstract}
An ecological study of age-standardized suicide rates in Belgian communities (1996-2005) was conducted using spatial regression techniques. Community characteristics were significantly related to suicide rates. There was mixed support for the social integration perspective: single person households were associated with higher suicide rates, while religious participation was unrelated and both immigration and the presence of non-European inhabitants had a negative impact. Deprivation had a positive relation with suicide. Population density had a negative influence on suicide rates. Areas with older populations had higher suicide risks than expected. A spatial contagion effect of neighboring communities was present for men. In the conclusion, hypotheses are presented on why an aging population could be associated with higher suicide rates in the community.
\end{abstract}

In recent years, various studies on community-level correlates of suicide rates have been published, without, however, leading to any final conclusions (Knox, Conwell, \& Caine, 2004; Rehkopf \& Buka, 2006). Most of these studies are based on American data and the number of studies on ecological correlates of suicidal behavior in a different cultural context remains rather limited (Agerbo, Sterne, \& Gunnell, 2007; Neeleman, 1998). The available evidence suggests that in developed countries, social integration indicators are strongly related to suicide rates (Fernquist \& Cutright, 1998; Helliwell, 2007). While in the older literature the focus was on traditional mechanisms of social inte-

Marc Hooghe and Bram Vanhoutte, Department of Political Science, University of Leuven, Leuven, Belgium.

Address correspondence to Marc Hooghe and Bram Vanhoutte, Dpt. Political Science, University of Leuven, Park Street 45, boîte 3602, Leuven, BE-3000, Belgium; E-mails: Marc. Hooghe@soc.kuleuven.be, Bram.Vanhoutte@soc. kuleuven.be. gration, such as organized religion, in the more recent literature attention is concentrated on social fragmentation and isolation, socioeconomic deprivation, and differences between rural and urban areas (Congdon, 1996; Evans, Middleton, \& Gunnell, 2004; Pescosolido \& Georgianna, 1989; Whitley, Gunnell, Dorling, \& Davey Smith, 1999).

We investigated the association between community-level indicators and suicide rates in the Flemish region of Belgium. Flanders has one of the highest suicide rates in Western Europe (14.7 per 100,000 inhabitants), roughly in line with the level of France (14.8 per 100,000 inhabitants), but markedly higher than in neighboring countries such as Germany $(9.8$ per 100,000$)$ and the Netherlands (8.7 per 100,000; all rates 2006). We focused on the local community as it can be argued that this level offers an effective small-scale interaction context for most residents and numerous statistical indicators are available, which allowed us to develop a comprehensive multivariate model. To avoid any misunderstandings, it must to 
be stressed that the current data do not allow us any interference at all about individual suicidal behavior. Our analysis therefore remains limited to observing meaningful associations between community characteristics and suicide rates within these communities.

We first review the literature on community-level differences in suicide rates, before presenting data and methods. Using a spatial regression model, we assessed the community-level correlates of suicide, before drawing conclusions, both with regard to the scholarly interest in suicide and community characteristics and the possible implications for preventive policies.

\section{LITERATURE}

Epidemiological evidence suggests the occurrence of strong and persistent social differences in suicide rates and this pattern by itself calls for a social study of suicide rates (Claassen et al., 2010; Helliwell, 2007; Mainon \& Kuhl, 2008). Although various studies are available on suicide rates at the local level in the United States, Canada, and the United Kingdom (Baller \& Richardson, 2002; Congdon, 1996; Kowalski, Faupel, \& Starr, 1987; Whitley et al., 1999), in continental Europe few studies are available, and most of these focus on an explanation of country-level diffusion patterns (Ferretti \& Coluccia, 2009). Although these countrylevel studies certainly have led to the development of new insights on the variation in suicide rates, it can be argued that they do not cover the full story. First of all, suicide rates show important variations within a society, and these important differences tend to be obscured if we only focus on national averages. Second, from a theoretical point of view, it can be argued that social integration is a process that occurs most intensively and successfully at the local level of neighborhoods or municipalities (Sampson, Morenoff, \& Gannon-Rowley, 2002). Third, meta-analysis has shown that the strongest associations between suicide levels and deprivation can be found in studies assessing the impact of the neighborhood or community level, not in studies that use the country level as an explanatory variable (Rehkopf \& Buka, 2006). This suggests that the most important social processes operate on the community level, not on a larger level of aggregation. By focusing on the community level, we return to one of the oldest traditions in suicide studies, where communitylevel integration was seen as one of the most important determinants of suicidal behavior (Durkheim, 1897; Johnson, 1965).

Previous research on the geographic area correlates of suicide rates suggests that three dimensions need to be taken into account: social integration, deprivation, and the rural-urban divide (Kelly \& Bunting, 1998; O'Reilly, Rosato, Connolly, \& Cardwell, 2008; Rehkopf \& Buka, 2006; Skapinakis, Lewis, Araya, Jones, \& Williams, 2005). One of the confounding elements in this line of study, however, is the tendency to rely on a composite indicator for geographic area characteristics, taking into account various indicators of deprivation, poverty, and exclusion simultaneously (Congdon, 1996; Congdon, 2009; O'Reilly et al., 2008). The risk associated with this approach is that it can obscure the precise correlates of suicidal behavior, as different kinds of community characteristics are lumped together. Therefore, we focused on distinct indicators in this study.

In the 1897 Durkheim study, a lack of social integration or isolation served as a main determinant of suicidal behavior. According to Durkheim (1897), religious participation could be taken as an indicator of social cohesion, as it was assumed that religious practice would have a strong community building effect (Burr, McCall, \& Powell-Giner, 1994). More recent statistical evidence confirms the relation between religious participation levels and suicide rates in the United States and in the Netherlands (Martin, 1984; Neeleman, 1998; Pescosolido \& Georgianna, 1989). It is assumed in these studies that the social ties that are strengthened by religious practice have an important 
effect in preventing social isolation (Robins \& Fiske, 2009).

Marital status too can serve as an indicator of social integration, and has been shown to have a strong negative correlation with suicide (Stack, 2000b). Apart from the direct influence on the individual level, the divorce rate may act as an indicator for the general quality of relational and family life in a community (Lester, 1995). Pescosolido and Wright (1990), on the other hand, found that a high proportion of never-married individuals was related to lower suicide rates among young men.

Migration and diversity may also serve as a measure for social integration (Helliwell, 2007). Internal migration, or moving from one city to another within a country, can uproot the individual from his or her community (Stack, 2000b). Immigration and an increasing ethnic and cultural diversity might have a negative effect on the quality and the intensity of social interaction within a community (Putnam, 2007; Trovato \& Jarvis, 1986). Even though more recent work challenges this claim (Hooghe, Reeskens, Stolle, \& Trappers, 2009; Twigg, Taylor, \& Mohan, 2010), it is still relevant to include this variable in the analysis.

Social deprivation usually is measured by including information on unemployment rates, low schooling, or average income in a community. The assumption is that enrollment in the labor market is associated with a valued role in society, which is not available to the unemployed (Agerbo et al., 2007). Similarly, poverty and socioeconomic exclusion have been shown to have a positive impact on suicide rates, at both the individual and the community level (Noh, 2009; Stack, 1982, 2000a).

The rural-urban divide has been a major topic of investigation in ecological suicide research. Traditionally, it was assumed that suicide rates would be higher in metropolitan areas (McCall \& Tittle, 2007; Weich, Twigg, \& Lewis, 2006). In a recent review of the literature, a curvilinear relation between urbanization and suicide was confirmed (Stack, 2000b). Research in the United
Kingdom suggested that especially in rural areas, suicide rates have increased strongly since the 1980s (Middleton, Gunnell, Frankel, Whitley, \& Dorling, 2003). In the United States, there are some indications that, especially for men, suicide rates tend to be higher in rural settings. One of the reasons for this shift might be the aging of the population in rural areas compared to the younger population of urban regions (Singh \& Siahpush, 2002). Qin, Agerbo, and Mortensen (2003), however, found that while in rural areas of Denmark suicide rates were higher for men than for women, the reverse was true for urban areas, where rates were higher for women than for men. In a study on Finland, the authors argued that the presence of mental health services might have an important negative effect on suicide rates in urban areas (Pirkola, Sund, Sailas, \& Wahlbeck, 2009).

Based on the literature, we can therefore hypothesize that suicide rates will be higher in communities with low levels of religious practice, in ethnically diverse communities, and in poor areas with high unemployment rates. In line with the classical literature, we still assume a positive relation between population density and suicide rates.

When studying community-level correlates of suicide rates, it is important to control for the confounding effects of gender and age composition. There are strong differences in suicide rates for women and for men. Men have higher rates than women, partly because men use more violent and thus more effective methods to commit suicide. Other factors explaining the gender gap in suicide rates are related to the male social role, associated with inadequate coping strategies such as emotional inexpressiveness or a reluctance to seek help (Bossuyt \& Van Calsteren, 2007; Hawton, 1998; Möller-Leimkühler, 2003). Therefore, in this study we conducted separate analyses of the suicide rates for men and for women.

Age too has an important impact on suicide rates, as suicide rates are about twice as high among those older than 80 than for younger age groups (Bossuyt \& Van 
Calsteren, 2007). Age composition might have an important confounding effect as the average age is higher in rural areas than that in urban centers (Moksony, 1990). To control for this composition effect, we used agestandardized suicide rates as dependent variables, taking age and gender composition effects into account. This implies that the mortality rates we used as a dependent variable in this study control for the fact that the risk of suicidal behavior is unequally spread across age groups.

\section{DATA AND METHODS}

We investigated age-standardized suicide mortality rates for 308 communities (with an average of 20,000 inhabitants) in the region of Flanders, Belgium, for the period 1996-2005. Our analysis is based on two distinct data sources. Suicide rates, based on official death certificates and confirmed by a medical doctor, which are considered to be very reliable, were one data source. In total, approximately 12,000 registered cases of suicide over this 10-year period were identified. The other data source was composed of community-level social cohesion indicators for each of the 308 municipalities in the region.

\section{Dependent Variable}

For the dependent variable, we used a smoothed version of the standardized mortality rates (SMR) for every community. To reduce random variation and minimize measurement error, we used average SMRs for a 10-year observation period (1996-2005). The SMR is the index of actual suicides over expected suicides for that community in the period under study. The expected suicide rate was calculated taking into account age and gender composition of the community, departing from the age specific average suicide rate in Flanders, and the average suicide rate in the Flemish region serves thus as reference point. To avoid outliers in the data caused by small municipality size, we used empirical Bayes prediction assuming a normal distribution (Clayton \& Kaldor, 1987), as is customary in epidemiological research. ${ }^{1}$ The advantage of using standardized rates is that both age differences in the composition of the population of a community and the population size are already integrated in the dependent variable, so that any correlation we might observe with age or population size would indicate a concentration effect instead of a composition effect. ${ }^{2}$

A suicide SMR over 100 indicates a higher occurrence of suicide than is to be expected, and a score less than 100 indicates a lower occurrence of suicide than is to be expected given the demographic composition in terms of age and gender of the community. We analyzed suicide rates for men and women separately, and the total rate for both genders combined. As male suicide rates were higher than female suicide rates, suicidal behavior among men disproportionally determined this overall indicator.

Data were collected in Flanders, the northern autonomous region of Belgium (population: 6,162,000 in 2008, or almost $60 \%$ of the Belgian population), by the Flemish Regional Agency for Health and Care. These data are only available at the regional level because suicide prevention is a regional competence.

\section{Independent Variables}

We included various variables at the community level as indicators for social integration, socioeconomic deprivation, and the rural-urban divide.

Looking at religious participation, we used a measure based on attendance figures of the Roman Catholic Church. This is the

1. This transformation increases the reliability of the SMR for small municipalities by borrowing strength from the total population (Riggan, Manton, Creason, Woodbury, \& Stallard, 1991).

2. It should be noted that an alternative analysis, using the crude suicide rates as a dependent variable, did not lead to different results. 
most prevalent religious affiliation in the strongly secularized region of Flanders. The actual indicator, measuring only the behavioral dimension of religion, is a factor score based on the ratio of participation in rituals such as baptism, marriage, funeral, and attendance at the Christmas Mass, averaged over two observations in 2006 and 2007 (Botterman \& Hooghe, in press). ${ }^{3}$ Although, strictly speaking, the observation period of this independent variable is situated 1 year after the observation period of the dependent variable, it is safe to assume that the regional variation in religious behavior is quite stable. It should be noted that in this region Catholicism is the only religion that can play a role on the community level, as the second most prevalent religion, Islam, is practiced by only about $3 \%$ of the population.

To operationalize a lack of marital or relational status integration, we included the rate of single households (i.e., all inhabitants registered as living alone, only one person living at that address). Furthermore, two different migration rates were used: the internal migration rate, measuring migration within Belgium; and the external migration rate, indicating migration from outside of Belgium. The rates are the sum of incoming and outgoing inhabitants in a community per 1,000 inhabitants. We used both rates, because on the community level they have a strong negative correlation (-.46) and thus clearly convey different information: communities attracting people already living in Belgium are apparently different from the communities attracting people from outside Belgium. We also included information on the presence of non-European inhabitants of the community, defined as not having the nationality of one of the 15 countries belong-

3. Weekly church attendance rates are not available for the observation period, but only for the year 2009. An analysis with the 2009 weekly church attendance rates on an average Sunday did not yield different results, as weekly attendance is highly correlated with other measurements of religious behavior. ing to the European Union in 1996, at the start of the observations. ${ }^{4}$

For deprivation, a number of variables were available, but most of them were strongly related and could not be used simultaneously in one analysis. In a preliminary analysis, we used average income level, unemployment rate, and average education level of the population one-by-one as unique community-level correlates. This analysis showed that the average income (in euro/ inhabitant) had the strongest relation with suicide rates, which is why we included it as an indicator for the socioeconomic status of the geographic area.

The rural-urban divide was measured by population density (inhabitants $\left./ \mathrm{km}^{2}\right)^{5}$ High population density creates anxiety, stress, and social disorganization (Levy \& Herzog, 1974). The squared and cubed values of population density were also included to detect curvilinear effects.

As a control variable, we included the ratio of elderly over the working age population, as we know elderly people are a population at risk for suicidal behavior. ${ }^{6}$

All variables used in the analysis are shown in Table 1.

4. Non-nationals from neighboring European countries are not perceived as foreigners by a large part of public opinion. Attitudes toward foreigners are mainly based on perceptions about non-Europeans or visible minorities residing in the community.

5. Population density was transformed into its natural logarithm to achieve a normal distribution.

6. To be able to separate the effect of having an older population from living in a single household, the residuals of the regression of the measure for an elderly population on the proportion of single households are used instead of the crude measures, to prevent multicollinearity. This means that the common variance of these two indicators is assigned to the proportion of elderly and not the proportion of single member households, thus leading to a very conservative test of the effect of single households. In this regard, it has to be remembered that because of different demographical dynamics, the percentage of elderly people is much higher in most Western European countries than that in the United States. 


\section{TABLE 1}

Variables Used in the Analysis

\begin{tabular}{|c|c|c|c|c|c|}
\hline Variable & Observations & Mean & Std. Dev. & Min. & Max. \\
\hline \multicolumn{6}{|l|}{ Dependent variables } \\
\hline Suicide mortality rate for men, $1996-2005$ & 308 & 98.38 & 9.65 & 78.11 & 130.14 \\
\hline Suicide mortality rate for women, 1996-2005 & 308 & 97.24 & 8.29 & 79.87 & 131.13 \\
\hline Total suicide mortality rate, $1996-2005$ & 308 & 97.69 & 11.02 & 77.13 & 133.55 \\
\hline \multicolumn{6}{|l|}{ Social integration } \\
\hline Religious participation (factor), 2006-2007 & 308 & 0.00 & 0.99 & -3.00 & 6.62 \\
\hline $\begin{array}{l}\text { Proportion of single households on } \\
\text { all households, 2000-2005 }\end{array}$ & 308 & 0.24 & 0.05 & 0.16 & 0.46 \\
\hline Internal migration rate/1,000, 2000-2005 & 308 & 1.45 & 3.98 & -13.26 & 15.67 \\
\hline External migration rate/1,000, 2000-2005 & 308 & 1.38 & 2.29 & -3.61 & 14.10 \\
\hline $\begin{array}{l}\text { Proportion non-EU inhabitants/1,000, } \\
\text { 1996-2005 }\end{array}$ & 308 & 9.54 & 12.47 & 1.12 & 84.36 \\
\hline \multicolumn{6}{|l|}{ Deprivation } \\
\hline Mean income (in 1,000 euro/inhabitant), 1996-2005 & 308 & 12.66 & 1.56 & 8.82 & 17.60 \\
\hline \multicolumn{6}{|l|}{ Rural/urban } \\
\hline Population density (ln), 1996-2005 & 308 & 5.97 & 0.72 & 3.94 & 8.07 \\
\hline \multicolumn{6}{|l|}{ Control composition effect } \\
\hline $\begin{array}{l}\text { Proportion of elderly }(65+) \\
\text { Percentage of population, 1996-2005 }\end{array}$ & 308 & 39.28 & 6.02 & 24.05 & 63.13 \\
\hline
\end{tabular}

Std. Dev., standard deviation; Min., minimum; Max., maximum; ln, natural logarithm.

Source: Standardized mortality rate (dependent): Flemish Regional Agency for Health and Care. All other variables: Social cohesion indicators in Flanders project, Bureau for Statistics Belgium and Flemish Department of Economy.

\section{PRESENTATION OF THE DATA}

A first look at the data suggests that community differences do exist. The SMRs, for men and women, in the 308 municipalities are mapped in Figures 1 and 2. While some communities have standardized mortality rates around 100 , others have a significantly higher or lower rate. There is clearly some variation in the stan-

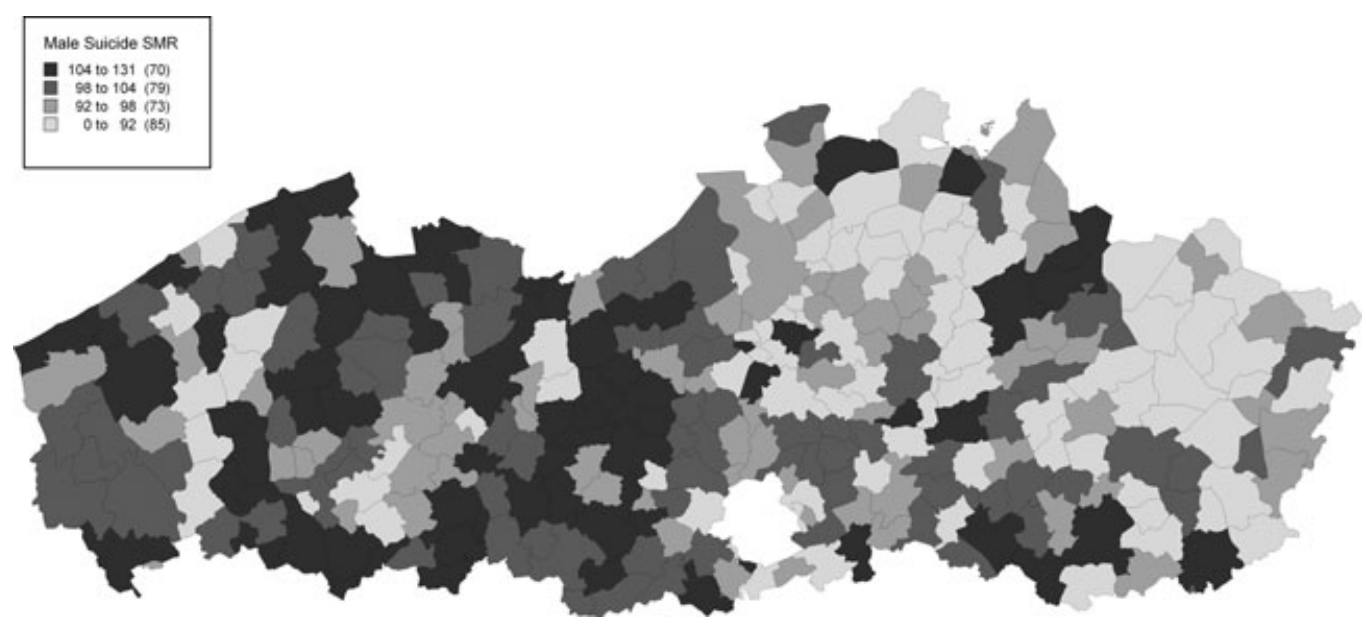

Figure 1. Standardized suicide mortality rates for men, 1996-2005. Source: Health Agency of the Flemish Region, Belgium. 


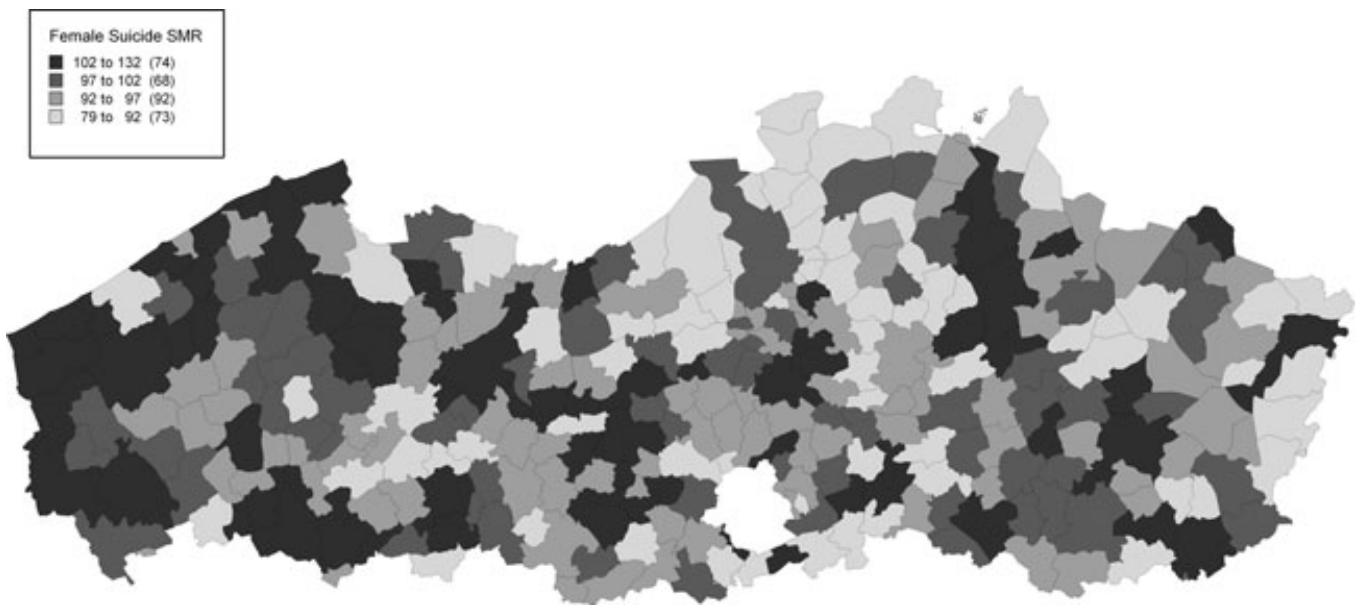

Figure 2. Standardized suicide mortality rates for women, 1996-2005.

Source: Health Agency of the Flemish Region, Belgium.

dardized mortality rates in the Flemish region.

Geographic clustering also can be observed: while the communities in the western part of the region (toward the coast and the border with France) seem to have high SMRs, these are consistently lower in the eastern part of the region (near the border with the Netherlands).

\section{METHODS}

To take account of the spatial nature of the data, spatial regression techniques will be used to analyze the data. At a more theoretical level, this technique allows us to investigate the nature of the spatial structure (Anselin, 1988; Haining, 2003).

Two forms of spatial models are commonly used to improve regressions on spatially correlated data. Theoretically, these two forms of spatial interdependence have a different interpretation. If two municipalities are adjacent, the suicide rate of one municipality can be influenced by that of the other. This means that there is a contagion or dispersion effect of suicide, represented best by a spatial lag model. If the error residuals of the municipalities are influenced by one another, this substantively means that the phenomenon under study is not analyzed at the correct geographic level, or that there might be an unobserved variable correlated with the spatial structure of the data. This implies a clustering effect, better analyzed by a spatial error model (Anselin, 1988).

It is impossible to fully specify a model with both a spatial lag and spatial error component, so a choice between a spatial lag or spatial error model has to be made. ${ }^{7}$ In the case of male and total suicide rates, a spatial lag model was clearly preferred over a spatial error model. This means that male (and total) suicide in one municipality is influenced by the male (and total) suicide rates of the neighboring municipalities. The diagnostics for female suicide rates are less clear, and while a spatial model for women is not absolutely necessary, it does not invalidate the results either. To compare our findings, however, we used a spatial lag model for all three suicide rates.

7. Computing Langrange multiplier tests on the residuals of a nonspatial ordinary least squares regression model helped determine whether a spatial lag or spatial error model was more appropriate (Anselin, Bera, Florax, \& Yoon, 1996). 


\section{ANALYSIS}

Applying spatial regression provides a clear insight to the community-level associations of suicide rates (Table 2). The spatial lag included in the model showed a moderate impact of neighboring communities for male and total suicide rates, and a rather small effect for female suicide rates. The standardized suicide mortality rate for men in a neighboring community had a positive effect on the male suicide rates, controlling for all other theoretically relevant variables. The current analysis does not provide informa- tion on the causal mechanism involved, but some form of copying behavior might play a role in this regard. The presence of an area with high suicide rates could make suicide more acceptable in the surrounding communities (Stack \& Kposowa, 2008). It is worth noting, however, that for women, this mechanism does not seem to be present to the same extent. This is probably due to the different patterns of suicidal behavior for women. As a larger percentage of suicide attempts does not lead to an actual suicide, the suicide rate might not be such a good indicator for female suicidal behavior.

TABLE 2

Spatial Lag Regression on Standardized Suicide Mortality Rates $(n=307)$

\begin{tabular}{|c|c|c|c|}
\hline & $\begin{array}{c}\text { Suicide } \\
\text { mortality rate } \\
\text { for men }\end{array}$ & $\begin{array}{c}\text { Suicide } \\
\text { mortality rate } \\
\text { for women }\end{array}$ & $\begin{array}{l}\text { Total suicide } \\
\text { mortality rate }\end{array}$ \\
\hline & Coef. (Robust SE) Sig. & Coef. (Robust SE) Sig. & Coef. (Robust SE) Sig. \\
\hline Cte. & $71.76(8.69)^{* * *}$ & $83.08(9.23)^{* * *}$ & $73.94(8.81)^{\star * *}$ \\
\hline \multicolumn{4}{|l|}{ Social integration } \\
\hline Religious participation & $-1.17(0.65)$ & $-0.40(0.45)$ & $-1.30(0.69)$ \\
\hline $\begin{array}{l}\text { Proportion of single } \\
\text { households }\end{array}$ & $103.79(17.90)^{* * *}$ & $82.62(15.13)^{\star * *}$ & $129.35(18.64)^{* * *}$ \\
\hline Internal migration rate & $-0.33(0.15)^{*}$ & $-0.24(0.15)$ & $-0.41(0.16)^{* *}$ \\
\hline External migration rate & $-0.83(0.22)^{* * *}$ & $-0.50(0.21)^{*}$ & $-1.05(0.22)^{\star * *}$ \\
\hline $\begin{array}{l}\text { Proportion } \\
\text { non-EU inhabitants/1, } 000\end{array}$ & $-0.15(0.05)^{* *}$ & $-0.11(0.05)^{*}$ & $-0.19(0.05)^{\star *}$ \\
\hline \multicolumn{4}{|l|}{ Deprivation } \\
\hline Mean income level & $-1.05(0.36)^{\star *}$ & $-0.92(0.31)^{\star *}$ & $-1.47(0.37)^{\star * *}$ \\
\hline Population density (ln) & $0.01(1.31)$ & $1.58(1.28)$ & $0.96(1.50)$ \\
\hline \multicolumn{4}{|l|}{ Rural/urban } \\
\hline $\begin{array}{l}\text { Population } \\
\text { density (ln) squared }\end{array}$ & $-1.87(0.62)^{\star *}$ & $-1.14(0.59)$ & $-2.32(0.68)^{\star *}$ \\
\hline $\begin{array}{l}\text { Population } \\
\text { density }(\ln ) \text { cubed }\end{array}$ & $-1.10(0.41)^{\star *}$ & $-0.66(0.44)$ & $-1.42(0.46)^{* *}$ \\
\hline \multicolumn{4}{|l|}{ Control composition effect } \\
\hline Proportion $65+$ & $0.48(0.10)^{* * *}$ & $0.36(0.08)^{* * *}$ & $0.62(0.10)^{* * *}$ \\
\hline \multicolumn{4}{|l|}{ Contagion effect } \\
\hline Spatial lag & $0.25(0.07)^{* * *}$ & $0.15(0.07)^{*}$ & $0.23(0.06)^{* * *}$ \\
\hline Squared correlation & .314 & .204 & .366 \\
\hline Log likelihood & -1075.8414 & -1050.3792 & -1103.9094 \\
\hline
\end{tabular}

Note. Entries are the result of a spatial lag regression, performed with tools for spatial data analysis in Stata written by Pisati (2001). The municipality of Voeren (6, 355 inhabitants) had to be excluded because it does not have a border with any other Flemish municipality. A two-tailed $z$ test was used to test significance. Coef. (Robust SE) Sig., coefficient (robust standard error) significance; Cte., constante; ln, natural logarithm.

$$
{ }^{*} p<.05,{ }^{* *} p<.01,{ }^{* *} p<.001
$$


The model is quite powerful, with an explained variance of $31 \%$ for men, $20 \%$ for women, and $37 \%$ for the total rate. The strongest community-level determinant of suicide rates was the proportion of single households in a community. A community with a higher proportion of single households had significantly higher suicide rates than one would expect based on the age-specific suicide rates, both for women and for men. This illustrates that a community with less dense networks of social support among its inhabitants has a significant chance to record higher suicide rates. A concentration of older inhabitants, too, had a positive effect on suicide rates. The dependent variable (standardized mortality rates) was already controlled for age-specific suicide rates, so that the effect observed here was not a compositional effect but a concentration effect. Municipalities with a higher proportion of older inhabitants had higher suicide risks for all age groups.

Furthermore, we can observe that population growth in the form of immigration toward the community had a strong negative impact on suicide rates. Immigration from both within and outside the country were negatively related to suicide rates for men; for women, only the foreign immigration had a significant negative effect. The proportion of inhabitants who do not have the nationality of one of the 15 original European Union member states also had a significant negative impact on suicide rates. Our findings contradict the results of earlier research suggesting a positive relation between migration and suicide rates. One possible explanation for this negative relation is that migrants commit less suicide and hence through their presence they lower the aggregate suicide rate. It is a well-established fact that migrants retain the suicide level of their home country (Sainsbury \& Barraclough, 1968), so this compositional effect is quite plausible for the non-European presence and external immigration in the Flanders region, as most non-European inhabitants and a large part of the external immigrants have Turkish and Moroccan origins. The largest group of external immi- grants in this area is from the Netherlands, which, just as Turkey and Morocco, has significantly lower suicide rates. For internal migration, we can imagine a similar mechanism, namely that people migrating within Belgium are less prone to suicide since they are wealthier and do not tend to be single. A second, more contextual, explanation is that places that attract migrants have a vibrant and attractive social life, functioning as a buffer against suicide rates. The opposite phenomenon, an area where more inhabitants are leaving than arriving, certainly seems a fertile ground for higher suicide rates. Furthermore, higher mean income lowers suicide rates. This illustrates that controlling for social integration, deprivation still plays a role, even in countries with a generous social security system such as Belgium. In this study, the relation with population density was nonlinear for men, as both the squared and cubic terms were significant. The cubic relation means that in densely populated areas of the region, with more than 600 inhabitants $/ \mathrm{km}^{2}$, suicide rates were significantly lower, while in sparsely populated areas, with less than 100 inhabitants $/ \mathrm{km}^{2}$, suicide rates were significantly higher, and in between they were relatively constant. Religious participation had no effect at all at the community level. ${ }^{8}$

Comparing suicide rates for women and for men, we found that most community characteristics had a similar direction, but the effects were weaker for women than for men.

\section{DISCUSSION}

The current analysis investigated the occurrence of significant community-level differences in suicide rates in Belgium. The smoothed standardized suicide mortality

8. When a one-tailed significance test was used, the degree of religious participation was significant $(p<.05)$ for male and total suicide rates, but to ensure comparability we adheres to standard statistical standards and interpreted twotailed significance tests. 
rates differ from 77 to 134 , suggesting a considerable amount of inter-community variance. With a squared correlation of $20 \%-36 \%$, our models are able to explain a substantial part of that variance. This by itself suggests that communities have an impact on suicidal behavior, which is often overlooked in policy programs aimed at preventing suicide. Most importantly, suicide rates tend to be higher in communities with higher proportions of single households, an older population, and a negative net migration. All these elements together indicate a higher risk for social isolation, which is a fertile ground for suicidal behavior. It should be noted that in the analysis we controlled for the variables that might be responsible for explaining a positive migration balance, like income levels. Two complementary explanations can be formulated and merit further investigation. A first plausible explanation is that the higher suicide rates found here are attributed to compositional differences in the population. Because migrants and non-single households have characteristics that lower their risk of suicidal behavior, on an aggregate level cities where these groups are more prevalent have lower suicide rates. A second and partly documented effect in this study is a concentration effect. Communities with a large proportion of elderly had a higher suicide rate than we would have expected on age-specific suicide rates alone. This means that the presence of a high proportion of elderly increases the suicide rate in total. In other words, the composition of a community translates itself into a less tangible but pervasive climate that influences suicide rates indirectly. The fact that the presence of an older population has such a strong effect might be related to feelings of "burdensomeness," which is considered as a main determinant of suicide (Joiner, 2005).

Contrary to other research, in this study the degree of religious involvement of a community had no effects. This means that in the highly secularized Flemish region, religious involvement does not seem to matter anymore for suicide rates, if adequate controls are used, although it should be noted that the effect of this variable comes close to significance. A relation between the urban character of a community and the suicide rate is suggested in the literature, although hypotheses on the direction of the impact of urbanity differs. In this analysis, in one of the most densely populated regions in Europe, no significant impact for women was found, but lower suicide rates were associated with densely populated communities for men. In this analysis, we did not rely on composite indicators, but rather on distinct variables. This allowed us to observe that the relation with migration and diversity is exactly the opposite of what is usually assumed in the literature. Diverse communities with high levels of immigration actually have lower suicide rates, and this might be due both to composition effects (i.e., lower suicide rates among ethnic minorities) and concentration effects (the fact that immigration signifies an attractive community). The current analysis suggests that community characteristics should be included in policies aimed at reducing suicide rates. Communities with older and isolated populations especially should be targeted in suicide prevention. It would be highly relevant to test if these community levels effects remain if individual information on victims of suicidal behavior is added. Only access to this kind of data can determine in a convincing manner whether the relations we found in this study are attributed to composition or concentration effects.

A last point is that, especially when looking at the male suicide rates, a moderate contagion effect among neighboring communities was present. This means that the suicide rate of a community is not only determined by endogenous factors, but also by the suicide rates in nearby communities. One of the elements in this regard might be that in regions with high suicide levels, the cultural acceptance of suicide is also higher. Although the mechanism behind this spatial influence is unclear, it underlines that context, here seen both as municipality of residence and the neighboring municipalities, contributes to circumstances that can facilitate or prevent suicide. 


\section{REFERENCES}

Agerbo, E., Sterne, J., \& Gunnell, D. (2007). Combining individual and ecological data to determine compositional and contextual socioeconomic risk factors for suicide. Social Science and Medicine, 64, 451-461.

Anselin, L. (1988). Spatial econometrics: Methods and models. Boston: Kluwer.

Anselin, L., Bera, A., Florax, R., \& Yoon, M. (1996). Simple diagnostic tests for spatial dependence. Regional Science and Urban Economics, 26, 77-104.

Baller, R., \& Richardson, K. (2002). Social integration, imitation and the geographic patterning of suicide. American Sociological Review, 67, 873-888.

Bossuyt, N., \& Van Calsteren, V. (2007). Epidemiology of suicide and suicide attempts in Belgium. International fournal of Public Health, 52, 53-157.

Botterman, S., \& Hooghe, M. (In press). Religion and voting behaviour in Belgium: An analysis of the relation between religious beliefs and Christian Democratic voting. Acta Politica; International fournal of Political Science, 46.

Burr, J., McCall, P., \& Powell-Giner, E. (1994). Catholic religion and suicide: The mediating effect of divorce. Social Science Quarterly, 75, 300-318.

Claassen, C., Yip, P., Corcoran, P., Bossarte, R., Lawrence, B., \& Currier, G. (2010). National suicide rates a century after Durkheim: Do we know enough to estimate error? Suicide and Life-Threatening Behavior, 40, 193-223.

Clayton, D. F., \& Kaldor, J. M. (1987). Empirical Bayes estimates of age-standardized relative risks for use in disease mapping. Biometrics, 43, 671-681.

Congdon, P. (1996). Suicide and parasuicide in London: A small-area study. Urban Studies, 33, 137-158.

Congdon, P. (2009). Explaining the spatial pattern of suicide and self-harm rates: A case study of east and south east England. Applied Spatial Analysis and Policy, 4, 23-43.

Durkheim, É. (1897). Le Suicide: Étude de sociologie. Paris: Alcan.

Evans, J., Middleton, N., \& Gunnell, D. (2004). Social fragmentation, severe mental illness and suicide. Social Psychiatry and Psychiatric Epidemiology, 39, 165-170.

Fernquist, R., \& Cutright, P. (1998). Societal integration and age-standardized suicide rates in 21 developed countries, 1955-1989. Social Science Research, 27, 109-127.
Ferretti, F., \& Coluccia, A. (2009). Socio-economic factors and suicide rates in European Union countries. Legal Medicine, 11, 92-94.

HaINING, R. (2003). Spatial data analysis. Cambridge: Cambridge University Press.

Hawton, K. (1998). Why has suicide increased in young males? Crisis, 19, 119-124.

Helliwell, J. F. (2007). Well-being and social capital: Does suicide pose a puzzle? Social Indicators Research, 85, 455-496.

Hooghe, M., Reeskens, T., Stolle, D., \& Trappers, A. (2009). Ethnic diversity and generalized trust in Europe. Comparative Political Studies, 42, 198-223.

Johnson, B. D. (1965). Durkheim's one cause of suicide. American Sociological Review, 30, $875-886$.

JoIner, T. (2005). Why people die by suicide. Cambridge: Harvard University Press.

Kelly, S., \& Bunting, J. (1998). Trends in suicide in England and Wales, 1982-1996. Population Trends, 92, 29-41.

Knox, K., Conwell, Y., \& Caine, E. (2004). If suicide is a public health problem, what are we doing to prevent it? American Journal of Public Health, 94, 37-45.

Kowalski, G., Faupel, C., \& Starr, P. (1987). Urbanism and suicide: A study of American counties. Social Forces, 66, 85-101.

Lester, D. (1995). Suicide, alcohol and divorce: A comment. Addiction, 90, 985-988.

Levy, L., \& Herzog, A. N. (1974). Effects of population density and crowding on health and social adaptation in the Netherlands. Fournal of Health and Social Behaviour, 15, 228-240.

Mainon, D., \& Kunt, D. (2008). Social control and youth suicidality. Situating Durkheim's idea in a multilevel framework. American Sociological Review, 73, 921-943.

Martin, R. L. (1984). Religiosity \& US suicide rates. Fournal of Clinical Psychology, 40, 1166-1069.

McCall, P., \& Tittle, C. (2007). Population size and suicide in U.S. cities: A static and dynamic exploration. Suicide and Life-Threatening Behavior, 37, 553-564.

Middleton, N., Gunnell, D., Frankel, S., Whitley, E., \& Dorling, D. (2003). Urbanrural differences in suicide trends in young adults: England and Wales, 1981-1998. Social Science and Medicine, 57, 1183-1194.

Moksony, F. (1990). Ecological analysis of suicide. In D. Lester (Ed.), Current concepts of suicide (pp. 121-138). Philadelphia: Charles Press.

Möller-LeimküHler, A. M. (2003). The gender gap in suicide and premature death or; 
Why are men so vulnerable? European Archive of Psychiatry and Clinical Neuroscience, 253, 1-8.

Neeleman, J. (1998). Regional suicide rates in the Netherlands: Does religion still play a role? International Fournal of Epidemiology, 27, 466472.

NoH, Y. H. (2009). Does unemployment increase suicide rates? The OECD panel evidence. Fournal of Economic Psychology, 30, 575-582.

O’Reilly, D., Rosato, M., Connolly, S., \& CARDWELl, C. (2008). Area factors and suicide: 5 year follow-up of the Northern Ireland population. British Fournal of Psychiatry, 192, 106-111.

Pescosolido, B., \& Georgianna, S. (1989). Durkheim, suicide and religion: Toward a network theory of suicide. American Sociological Review, 54, 33-48.

Pescosolido, B., \& Wright, E. (1990). Suicide and the family over the life course. Family Perspectives, 24, 41-58.

Pirkola, S., Sund, R., Sailas, E., \& WahlBECK, K. (2009). Community mental-health services and suicide rate in Finland: A nationwide small-area analysis. The Lancet, 373, 147-153.

Pisati, M. (2001). Tools for spatial data analysis. Stata Technical Bulletin, 60, 21-37.

Putnam, R. (2007). E pluribus unum: Diversity and community in the twenty-first century. Scandinavian Political Studies, 30, 137-174.

Qin, P., Agerbo, E., \& Mortensen, P. (2003). Suicide risk in relation to socioeconomic, demographic, psychiatric and familial factors. British fournal of Psychiatry, 17, 546-550.

RehKopf, D. H., \& BuKa, S. L. (2006). The association between suicide and the socioeconomic characteristics of geographical areas: A systematic review. Psychological Medicine, 36, 145157.

Riggan, W., Manton, K., Creason, J., Woodbury, M., \& STallard, E. (1991). Assessment of spatial variation of risks in small populations. Environmental Health Perspectives, 96, 223-238.

Robins, A., \& Fiske, A. (2009). Explaining the relation between religiousness and reduced suicidal behavior. Suicide and Life-Threatening Behavior, 39, 386-395.

Sainsbury, P., \& Barraclough, B. (1968).

Differences between suicide rates. Nature, 220, 1252.
Sampson, R. J., Morenoff, J., \& GannonRowley, T. (2002). Assessing 'neighborhood effects': Social processes and new directions in research. Annual Review of Sociology, 28, 443-478.

Singh, G., \& Siahpush, M. (2002). Increasing rural-urban gradients in U.S. suicide mortality, 1970-1997. American Fournal of Public Health, 92, 1161-1167.

Skapinakis, P., Lewis, G., Araya, R., Jones, K., \& Williams, G. (2005). Mental health inequalities in Wales, UK: Multi-level investigation of the effect of area deprivation. British Fournal of Psychiatry, 186, 417-422.

STACK, S. (1982). Suicide: A decade review of the sociological literature. Deviant Behavior, 4, 41-66.

STACK, S. (2000a). Suicide: A 15-year review of the sociological literature. Part I: Cultural and economic factors. Suicide and LifeThreatening Behavior, 30, 145-162.

STACK, S. (2000b). Suicide: A 15-year review of the sociological literature. Part II: Modernization and social integration perspectives. Suicide and Life-Threatening Behavior, 30, 163-176.

Stack, S., \& Kposowa, A. (2008). The association of suicide rates with individual level suicide attitudes: A cross national analysis. Social Science Quarterly, 89, 39-59.

Trovato, F., \& Jarvis, G. K. (1986). Immigrant suicide in Canada, 1971 and 1981. Social Forces, 65, 433-457.

Twigg, L., Taylor, J., \& Mohan, J. (2010). Investigating perceptions of antisocial behavior and neighborhood ethnic heterogeneity in the British Crime Survey. Transactions of the Institute of British Geographers, 35, 59-75.

Weich, S., TWigG, L., \& LeWIs, G. (2006). Rural/non-rural differences in rates of common mental disorders in Britain. British fournal of Psychiatry, 188, 51-57.

Whitley, E., Gunnell, D., Dorling, D. \& Davey Smith, G. (1999). Ecological study of social fragmentation, poverty and suicide. British Medical fournal, 319, 1034-1037.

Manuscript Received: March 15, 2011

Revision Accepted: April 19, 2011 